Educación Física y Ciencia, vol. 21, nº 1, e071, enero-marzo 2019. ISSN 2314-2561

Universidad Nacional de La Plata.

Facultad de Humanidades y Ciencias de la Educación.

Departamento de Educación Física

\title{
Sentidos da dança: concepções de alunos de educação física
}

Senses of the dance: conceptions of students of physical education

Ana Carolina Vianna Kunz

Ciências da Atividade Física, Universidade Salgado de Oliveira, Brasil

anacarolina.kunz@gmail.com

Carlos Alberto Figueiredo da Silva

Ciências da Atividade Física, Universidade Salgado de Oliveira, Brasil

ca.figueiredo@yahoo.com.br

Renata Osborne

Ciências da Atividade Fisica, Universidade Salgado de Oliveira, Brasil

rerafadeo@gmail.com

Adriana Martins Correia

Educaçâa Física, Universidade Federal Fluminense, Brasil

adricorreia@uol.com.br

\section{Resumo:}

O objetivo deste estudo foi analisar o processo de apropriação do conteúdo dança pelos alunos de um curso de licenciatura em Educação Física, a partir da investigação de um processo de intervenção pedagógica. Trata-se de uma pesquisa com abordagem qualitativa. A coleta dos dados deu-se a partir de uma entrevista semiestruturada em um grupo focal constituído por 12 sujeitos. Evidências apontam quatro apropriações: 1) modificação de percepção a respeito das atividades práticas e compreensão da importância da fundamentação teórica; 2) a dança representa para maioria um terreno desconhecido, gerando insegurança, medo de exposição e resistência à participação; 3) há preconceito relacionado às questões étnico-raciais, de gênero e religiosas; 4) há valorização à fruição estética.

PalaVras-ChaVe: Dança, Educação Física, Formação Profissional.

\section{ABstraCT:}

The purpose of this study was to analyse the process of appropriation of dance content by students of a degree in Physical Education, from the investigation of a process of pedagogical intervention. This research was carried out with a qualitative approach. The data collection was based on a semi-structured interview in a focal group composed by 12 people. Evidence indicates four main appropriations that: 1 ) there is a modification of perception regarding practical activities and understanding of the importance of theoretical foundation; 2) dance represents for the majority an unknown terrain, generating insecurity, fear of exposure and resistance to participation; 3) there is prejudice related to ethnic-racial, gender and religious issues and 4) there is valuation to the aesthetic fruition.

KeYWORDS: Dance, Physical Education, Vocational Training.

\section{INTRODUÇÃO}

A dança, desde a gênese da Educação Física brasileira, esteve presente como componente curricular nas escolas. Inicialmente, surgiu como sinônimo da própria disciplina, quando destinada a um público feminino e de elite, representando uma das poucas formas de atividade física socialmente tolerada para as moças (Pacheco, 2008). 
Neste cenário, aparecia com o nome de ginástica geral e ginástica rítmica, indicando a generificação deste conteúdo, que dava sentido à divisão das turmas de acordo com o sexo e, consequentemente, formando currículos distintos para homens e mulheres (Campos, 2009; Correia; Votre; Oliveira, 1998).

A partir da chamada crise da Educação Física (EF), na década de 1980 (Daolio, 1997), a dança tem sido entendida como uma das categorias que constituem os blocos de conteúdo desta disciplina, juntamente com o esporte, a ginástica, o jogo e a luta. A evidenciação desta categorização é postulada no livro Metodologia do Ensino da Educação Física (Coletivo de Autores, 1992), obra que buscava superar o paradigma esportivista e tecnicista que dominava o cenário da Educação Física brasileira. Os Parâmetros Curriculares Nacionais - Educação Física (PCN) são publicados logo a seguir, marcando mais uma vez esta preocupação com a diversificação dos conteúdos (Brasil, 1997).

O processo epistemológico de retomada do conteúdo dança nas aulas de educação física, a partir das abordagens teóricas pós-década de 1980, mostra que cada vez mais há uma necessidade de ampliação dos estudos relacionados aos espaços e contextos educacionais, para que se produzam novos conhecimentos a fim de esclarecer questões ainda pouco discutidas. No entanto, no cotidiano das práticas esta amplitude de temas esbarra em questões como formação profissional, tradição e consenso sobre o que deve ser a EF enquanto componente curricular. Frequentemente o professor de educação física egresso da formação considera-se sem domínio da linguagem de dança para utilizá-la como estratégia nas aulas que ministra (Gomes, 2007).

É necessário tentar se reconstruir o espaço e as possibilidades de trabalho da dança na escola, superando sua representação como sinônima de coreografias em eventos escolares, para, de fato, ser elemento presente nas aulas e integrante do currículo da Educação Física escolar.

Este estudo foi estruturado em função da disciplina Prática Pedagógica 1 (PP1). Esta disciplina representa a quarta parte das 400 horas de práticas pedagógicas determinadas pela legislação que regulamenta a formação dos professores da Educação Básica no Brasil (Resolução CNE/CES 02 de 2002). Na PP1, a proposta é integrar os conhecimentos relativos à Dança (disciplina realizada no período anterior) aos temas transversais Sexualidade e Pluralidade Cultural.

Através da proposta de laboratórios didáticos se cria a simulação de situações-problema que são as referências para elaboração de atividades de aula de Educação Física. As atividades das práticas pedagógicas devem ser realizadas em grupo e ter o formato de microensino.

A disciplina incrementa as referências teóricas específicas de cada um dos conteúdos, neste caso, a Dança. O diálogo entre a prática e a teoria das práticas pedagógicas oferece um espaço propício para os alunos exercitarem sua capacidade reflexiva, crítica e criativa, fundamental na complexidade deste processo de formação. $\mathrm{O}$ docente como mediador desse processo de construção ajuda os futuros professores a criarem estratégias para lidar com as mais diversas situações do cotidiano escolar. As reflexões e ações cunhadas pelos alunos na tentativa de lidar com suas limitações pessoais no processo educativo são levadas para sua prática profissional e transformadas em estratégias criativas além do aprofundamento nos diferentes conteúdos.

A disciplina PP1 é o primeiro contato do licenciando com a sua mudança de papel, os alunos neste momento passam a ocupar o lugar de professor e ocorre no $4^{\circ}$ semestre do curso (segundo ano). A partir dessa mudança de posição, começam a perceber quais são as reais demandas desta função. A proposta metodológica aqui descrita tentou tornar, a todo o momento, o "aluno-professor" protagonista na busca desse novo saber. Os conteúdos teóricos foram introduzidos e apresentados a partir das próprias necessidades encontradas para a elaboração das práticas e atividades propostas pela disciplina. Desta forma, buscou-se dar um real sentido às necessidades, tornando esse aprendizado mais significativo.

O objetivo do presente estudo é analisar o processo de apropriação dos conhecimentos relativos à dança, ao longo da vivência na disciplina Prática Pedagógica 1 - Dança, por parte de alunos de um curso de licenciatura em educação física. 
Duas questões nortearam o processo de investigação: a) que representações os alunos têm em relação ao papel da dança na formação do professor de educação física?; b) quais são os sentidos da dança, enquanto conteúdo das aulas de Educação Física, que o grupo de alunos constrói ao longo da vivência na disciplina prática pedagógica da dança?

O estudo justifica-se na medida em que pretende identificar caminhos para apontar alternativas a um cenário instalado na realidade da Educação Física brasileira quando se trata do conteúdo dança. Esta, mesmo estando presente nos PCN, ainda é pouco utilizada como ferramenta educacional pela grande maioria dos professores de educação física no dia a dia da escola.

\section{MÉTODO E MATERIAIS}

\section{Caracterização do estudo}

Trata-se de uma pesquisa qualitativa que se caracteriza por ser exploratória e descritiva, tratada em uma perspectiva educacional. Sendo assim, buscou-se entender os sentidos e os significados atribuídos pelos sujeitos pesquisados no processo de investigação.

A pesquisa qualitativa é uma atividade sistemática orientada à compreensão em profundidade de fenômenos educativos e sociais, à transformação de práticas e cenários socioeducativos, à tomada de decisões e também ao descobrimento e desenvolvimento de um corpo organizado de conhecimento (Sandin Esteban, 2010).

Entende-se por pesquisa exploratória aquela que o pesquisador pretende elucidar e ampliar os conhecimentos acerca do tema pesquisado, com o objetivo de esclarecer e buscar maior entendimento sobre o problema estruturado (Gil, 2004). A pesquisa descritiva tem a finalidade de expor as características de determinado grupo ou dos fenômenos investigados. Esse tipo de pesquisa pode ter como objetivo investigar opiniões, atitudes e crenças de um determinado grupo buscando uma nova compreensão acerca do problema traçado. As pesquisas descritivas de caráter exploratório estão associadas a pesquisadores sociais preocupados com a atuação prática (Gil, 2004).

A pesquisa aqui desenvolvida foi delineada a partir da necessidade de ampliação dos estudos relacionados aos espaços e contextos educacionais, para que se produzam novos conhecimentos a fim de esclarecer questões ainda pouco discutidas no contexto da Educação Física a respeito do fenômeno dança. Para isso é necessário que se proponham também discussões a respeito de outras questões que estão presentes nesse contexto: formação profissional, tradição e consenso sobre o que deve ser a EF enquanto componente curricular.

$\mathrm{Na}$ presente pesquisa, o grupo investigado faz parte de uma turma do curso de licenciatura em Educação Física de uma faculdade particular, situada na zona norte do município do Rio Janeiro. O grupo foi observado durante o semestre em que os alunos cursaram a disciplina Práticas Pedagógicas 1.

Para Alves-Mazzotti e Gewandsznajder (2000, p. 162), "neste tipo de pesquisa a escolha dos participantes é proposital, isto é, o pesquisador os escolhe em função de questões de interesse do estudo e também das condições de acesso e permanência no campo e disponibilidade dos sujeitos".

Consideramos a importância das "experiências de aprendizagem", para isso os trabalhos foram realizados dentro da proposta de laboratório didático. Essas experiências serviram como base para análise e discussão dos resultados. As questões que surgiram, a partir de uma situação real de ensino, se articularam aos conhecimentos teóricos de forma direta a fim de esclarecer os apontamentos do processo de pesquisa. 


\section{Instrumentos}

No início da pesquisa foi aplicada aos alunos da disciplina uma ficha individual para caracterização do perfil do grupo em relação à idade e ao sexo. Este instrumento também contou com uma questão fechada sobre a experiência do informante no universo da dança.

A fase intermediária da pesquisa, de intervenção mais efetiva, foi composta por aulas da disciplina Prática Pedagógica 1 - Dança, cujo formato é baseado em um sistema de laboratório pedagógico, na qual os graduandos montam e apresentam suas atividades para o resto do grupo, a partir das vivências de práticas propostas pela professora, de leituras de textos e de filmes, além de seus repertórios de experiências adquiridos em seu cotidiano na universidade e fora dela. $\mathrm{O}$ material teórico-prático apresentado pela professora constituiu-se principalmente a partir das concepções de ensino da dança propostas por Marques $(2001,2006)$ e Laban (1978).

Esta vivência foi registrada em um diário de campo, que forneceu os subsídios para a construção do relato de experiência apresentado posteriormente. Neste diário a pesquisadora relatou os acontecimentos e fato ocorridos no campo de pesquisa, bem como falas e reflexões dos alunos durante a realização das aulas. Desta forma, a pesquisadora cumpriu o papel de observador-participante. Para Alves-Mazzotti e Gewandsznajder (2000), neste tipo de intervenção o nível de participação do observador é bem variável, podendo alterar também o nível de exposição de seu papel como observador aos membros do grupo estudado.

$\mathrm{Na}$ parte final da pesquisa foi selecionado um grupo de alunos, para participar de uma entrevista, utilizando-se a técnica do grupo focal para coleta de dados. As respostas e questóes levantadas pelos alunos foram gravadas e transcritas, para se garantir uma maior confiabilidade e fidedignidade dos relatos, mas também para facilitar a elucidação dos temas expostos pelo grupo durante a análise dos dados. Gaskell e Bauer (2002) afirmam que a "transcrição da entrevista é vital para que toda a informação esteja enraizada na própria entrevista de tal modo que, quando a análise é feita o corpus pode ser trazido para justificar as informações" (p.86).

O grupo focal contou com 12 alunos da disciplina, no qual se utilizou um roteiro de entrevista semiestruturada de questões, ao mesmo tempo em que se permitiu e se valorizou o surgimento de outras questões colocadas pelos alunos sobre a experiência na disciplina. Para Gaskell (2002), o objetivo do grupo focal, onde o entrevistador é chamado de moderador ou catalizador, é estimular os participantes a falar ou reagir a partir do que foi falado por outros elementos do grupo. Podemos dizer que neste tipo de pesquisa "os sentidos ou representações que emergem são mais influenciados pela natureza social da interação com o grupo" (p.75).

\section{População e amostra}

A população da pesquisa se constituiu dos alunos da disciplina Prática Pedagógica 1. Inicialmente 53 pessoas preencheram a ficha de caracterização do perfil do aluno e, destas, 50 participaram efetivamente das aulas observadas. O grupo focal constituiu-se de 12 alunos deste universo, contando com aqueles que se voluntariaram para a entrevista.

O delineamento desta pesquisa pautou-se pela abordagem qualitativa, com a imersão do pesquisador de forma direta no ambiente natural. O projeto desta pesquisa foi submetido ao comitê de ética da Universidade Salgado de Oliveira, tendo sido aprovado sob o número 37025314.6.0000.5289. 


\section{RESULTADOS E DISCUSSÃO}

As fichas revelaram discreta maioria do sexo masculino, $58 \%$ (29) e $42 \%$ (21) do sexo feminino. As idades variavam entre 18 a 45 anos. O primeiro item seguinte da ficha versava sobre como os alunos avaliavam sua vivência em relação à dança. Em sua maioria 60\% (30), responderam que têm afinidade com a dança, mas nenhum tipo de formação anterior. Em seguida, $28 \%$ (14) dos alunos marcaram a opção que os definia como não tendo afinidade com a dança e nenhum tipo de formação anterior. $8 \%$ (4) responderam que tiveram formação em dança anterior a educação física mas não tiveram experiência profissional e/ou artística, e somente $4 \%$ (2) tiveram formação anterior à educação física e tiveram também experiência profissional e/ ou artística na área.

Pode-se identificar que a maioria dos alunos não possuía vivência anterior com relação à dança. O processo de ressignificação do conteúdo passa em um primeiro momento por uma experiência inaugural, já que os significados que tinham a respeito deste fenômeno se formaram de forma externa à vivência pessoal. Por isso, era necessário que esses alunos tivessem em primeiro lugar condições de vivenciar empiricamente este conteúdo em suas dimensões, para posteriormente conseguir perceber como seria possível compreendê-lo dentro do processo educativo. A realidade encontrada no grupo estudado permitiu perceber a necessidade de estratégias que levassem os alunos a uma construção pedagógica consistente e que fornecesse subsídios para que desenvolvessem tal competência.

\section{Análise do grupo focal}

A primeira questão direcionada ao grupo propôs que expusessem quais eram as expectativas pessoais quanto à disciplina prática pedagógica, considerando os tipos de conteúdos práticos e teóricos, e o que esperavam ter contato no momento inicial da disciplina. Nos relatos aparece claramente a ideia de que a disciplina iria trazer aulas práticas, "passos de dança" que pudessem ensinar na escola; textos prontos ou um repertório de passos que seriam aprendidos pelos alunos-mestres e que seriam retransmitidos em suas vivências profissionais. A fala de uma aluna reforça a ideia do texto pronto: "Achei que fosse só prática aprender alguns passos práticos e alguns ritmos”. Outra questão levantada pelos alunos foi a quantidade de aulas teóricas "[...] não imaginei que fosse tão teórico" Este fato mostra uma dificuldade de os alunos perceberem a importância da fundamentação teórica dentro do processo de construção e organização do conhecimento específico.

A segunda pergunta realizada indagava ao grupo quais foram as maiores dificuldades encontradas no decorrer do processo. Dentre as questões levantadas, a mais relevante foi a dificuldade de trabalhar com um conteúdo com o qual não possuíam um conhecimento prévio. "Você precisa passar uma coisa que você não conhece, o desconhecido... O Hip-Hop, por exemplo, eu achava que era uma coisa básica, mas não, se divide em vários tipos de movimentos". O relato desse aluno nos ajuda a perceber como é necessária maior vivência sobre o conteúdo, já que, como nos mostra a primeira questão objetiva do questionário de entrada, a grande maioria do grupo nunca teve contato pessoal com a dança. $\mathrm{O}$ mesmo aluno conclui sua reflexão da seguinte forma "Existem outras coisas por trás que a gente não conhecia, a dificuldade é essa...". Essa fala começa a identificar a necessidade de maior aprofundamento e pesquisa sobre o conteúdo, tema esse enfatizado na pergunta seguinte.

Outra grande dificuldade apontada pelos alunos foi a dificuldade para realização dos trabalhos em grupo. Pontuaram os diversos problemas que enfrentaram para organização e execução das propostas da disciplina levantando questões como: dificuldade de conciliar horários, falta de comprometimento dos integrantes do grupo e divergência de opiniões como principais motivos de impedimento para o bom andamento dos trabalhos. 
Ao perguntarmos como enfrentaram tal obstáculo, notamos outra palavra muito significativa: pesquisa. $\mathrm{O}$ relato a seguir ajuda a perceber como o encaminhamento metodológico proposto motivou uma perspectiva mais investigativa no processo ensino-aprendizagem: "Pesquisando e resolvendo os problemas do grupo éfunção da pesquisa. Tínhamos que fazer o trabalho!". Além da questão anterior aparece também de que forma as trocas em grupo podem ampliar e facilitar a construção dos conhecimentos, ajudando a conciliar as diferentes percepções e enriquecendo o processo criativo. Neste sentido, parece que a dança como território do 'desconhecido' foi um elemento motivador nesta valorização do processo de pesquisa. "[...] Todo mundo criou e todo mundo teve essa experiência de professor de ensinar o outro. A busca é de quem está ensinando... Aprender a buscar as informações, o desconbecido dá medo mais dá oportunidades de buscar, se aprofundar e aprender uma coisa que leva para a vida inteira. Pesquisando, discutindo e acabando resolvendo os problemas do grupo. A pesquisa, e absorvendo as informaçóes um com o outro... Coletividade [...]".

O entendimento de que a formação do professor passa por um processo contínuo de pesquisa e que esse processo fará parte também de seu cotidiano profissional é de extrema importância. Perceber que cada profissional deverá construir em sua trajetória acadêmica os seus meios para buscar o aperfeiçoamento dá a ele condições de ser mais autônomo dentro deste processo. "A PP foi excelenteporque mostrou o início de tudo, inicio da formação do professor, mostrou o esqueleto de como montar uma aula, nós sabemos onde pesquisar, onde procurar, que base seguir pra montar uma aula. Independente da aula, independente da dança se for Jongo, se for samba, se for frevo ou rock, em qualquer outro tipo de atividade, nós vamos ter um embasamento teórico e saber certinho como procurar [...]".

Esses alunos já percebem que tão ou mais importante do que dominar a técnica das danças na escola, fazse necessário investigar e motivar a investigação entre seus alunos, como destaca uma aluna: "[... se eu tiver que dar aula de balé clássico, eu não sei dar aula de balé clássico, mas sei de um caminho para desenvolver essa atividade [...] fazer um workshop daquela aula. Ensinou os caminhos para buscar os nossos objetivos".

Este relato nos permite perceber que alguns alunos também identificaram uma necessidade pessoal de diversificar suas vivências corporais como uma forma de ampliar seus conhecimentos. "A PP me ajudou para um aprofundamento. Pude identificar os tipos de dança, conhecer mais. Percebi a necessidade de aperfeiçoar meus movimentos e procurar novos movimentos e treinar. Fui até procurar uma escola de dança, me interessei e estou fazendo aula de Hip Hop. O profissional de EF não pode ficar preso só a uma área, ele ter que saber um pouco de tudo".

Identifica-se também a importância que os alunos atribuem ao aprendizado construído coletivamente. $\mathrm{O}$ grupo manifestou-se positivamente, concordando com um colega que afirmou que "A troca foi o principal".

Na pergunta seguinte, os alunos foram questionados se a disciplina propôs uma forma de ensinar a dança diferente da que eles vivenciaram em sua realidade escolar. A resposta dos alunos foi afirmativa e para eles a palavra que define essa alternativa a forma tradicional é "a liberdade de expressar-se e criar".

Surgiram referências à necessidade da noção técnica para o encaminhamento das aulas e com base nestas colocações foi perguntado ao grupo se o sistema Laban poderia ser utilizado como uma opção para essa ferramenta 'técnica' apontada por eles. A resposta a esta pergunta também foi positiva e os alunos ressaltaram que o "Laban utiliza os movimentos naturais e o professor pode criar formas de trabalhar com o método dele". Quando falam 'movimentos naturais', fica claro que esses alunos estabelecem uma relação direta com a pesquisa do movimento, liberdade de expressão e criação. Ainda nesta reflexão sobre a possibilidade de utilizar Laban como alternativa à técnica, uma aluna reforça essa idéia: "[...] Laban acaba sendo o cerne de tudo, o centro, na falta de uma outra coisa você lembra logo, sempre tem uma ideia dele que dá pra usar".

A outra questão levantada para o grupo foi interrogar como a vivência na disciplina poderia ser levada para a prática profissional. $\mathrm{Na}$ resposta a essa questão os alunos foram unânimes em ressaltar novamente a experiência do trabalho em grupo. Mesmo sendo identificado anteriormente como responsável por uma das grandes dificuldades encontradas pelo grupo para a realização das atividades, o fazer coletivo é apontado pelos 
alunos como um dos grandes aprendizados que serão levados para a prática profissional. "A gente aprende muito com as experiências do outro mais do que com a técnica [...]".

A questão didático-pedagógica também foi destacada pelo grupo. Esses alunos pontuaram que a disciplina foi muito importante para a compreensão da dança em uma perspectiva pedagógica relacionada ao conhecimento dos instrumentos didático-metodológicos. Em função de os alunos não terem passado pela disciplina didática esse foi o primeiro contato formal com esses elementos, o que representou uma importante ferramenta na construção de alguns conhecimentos adquiridos. Essa importância se evidencia no relato a seguir: "A experiência em PP foi melhor do que a da dança, a gente experimentou como se monta plano de aula, pensar mais analisar os métodos de ensino o, a execução, que é mais adequada a cada faixa etária. A experiência foi muito ampla em aprendizado".

Ainda dentro da temática da didática e da fundamentação teórica, os alunos identificam a necessidade de articulação de diferentes conteúdos teóricos para se produzir uma aula, este aspecto destaca a importância do conhecimento teórico, que no princípio da entrevista foi destacado como excessivo.

A fundamentação teórica, aliada aos conhecimentos didáticos e às vivências de caráter estético em relação à arte e à educação, são extremamente importantes para um aprendizado com o objetivo de construir sentidos e significados. As transformações que ocorrem dentro deste processo permitem um posicionamento mais aberto e flexível dos futuros docentes, característica fundamental para conhecer e acompanhar as transformações sociais que farão parte de seu cotidiano profissional. "[...] foi bem proveitoso. Percebi a necessidade de, é conseguir implementar e fazer a conexão. Por exemplo: Isabel Marques, Paulo Freire, e esses todos pensadores. Porque na hora que a gente tinha que montar um planejamento ou um relatório e juntar isso tudo em uma coisa só ficou meio complicado [...] A questão do conbecimento fez eu abrir um leque, ver de uma forma diferente. Entendi que não era só a questão do tempo, dos fatores de movimento, os princípios. A gente tinha que juntar isso para aprender e ensinar isso para os nossos alunos".

Podemos identificar essa primeira experiência no papel de professor como um 'marco' extremamente significativo na formação destes futuros docentes. Esses passam a ter uma pequena noção da amplitude dos conhecimentos necessários para a prática profissional, além da necessidade de articular diferentes conhecimentos para a elaboração do trabalho. "No final da PP você se descobre como profissional, e agora eu sou professor, sai do lugar de aluno, eu agora vou buscar os meus recursos as minhas informaçóes para ensinar aos meus alunos agora eu vou multiplicar os conhecimentos. Na dança eu não tinha essa percepção".

Diante disso foi perguntado se consideravam que a disciplina prática pedagógica I (PPI) deu condições a eles de elaborarem uma atividade pedagógica de dança, para além das tradicionais coreografias prontas. Em sua grande maioria os alunos responderam afirmativamente. Esse fato indica que esses alunos-mestres começam a ter a percepção de que o professor não necessariamente precisa dominar um rol de repertórios coreográficos e de conhecimentos sobre as várias formas de danças existentes para que possam ensinar.

O tema seguinte visou identificar se através da disciplina os alunos-mestres conseguem ter alguma percepção de como poderão aplicar esta concepção de dança no espaço escolar. Esses, em sua maioria, entenderam que sim, porém, levantaram alguns questionamentos que foram frutos das próprias discussóes provocadas durante as aulas e também da vivência de alguns alunos já inseridos no espaço escolar. Como desenvolver uma proposta que identifica o aluno como centro de um processo criativo e reflexivo, em um contexto escolar que ainda entende a dança como 'produto' apresentado pelo professor de educação física em datas festivas? Os alunos que já vivenciam a realidade da escola percebem que existe uma expectativa por parte das instituições de que a dança continue a ocupar o espaço que sempre foi atribuído a ela, enquanto um adorno de eventos escolares.

A partir daí, o grupo se encaminhou no sentido de aprofundar o debate: como introduzir na escola a dança como conteúdo um conteúdo de um processo de aprendizagem consistente, que supere esta dimensão eventual que ainda hoje prevalece? "[... ] eu percebo que quando chega lá [na escola] o que importa é o resultado final, o produto. As escolas, o sistema, estão mais preocupadas com o produto do que a formação da criança. A 
dança abrange a cultura, tem muito mais a ensinar do que coreografiazinh a pro papai tirar foto e ficar bonito. $A$ gente aprende isso e chega lá com essa sede de ensinar. Lá encontra uma parede de motivos pra te impedir e isso te enfraquece... o que a gente aprende aqui na universidade liberta. O ensino, a educação liberta mesmo, mas acaba libertando só a gente dependendo de onde a gente tá".

Em seguida o tema do debate foi conduzido para a questão da dança relacionada ao tema transversal pluralidade cultural, que é conteúdo previsto na ementa da disciplina. As respostas dos alunos mais uma vez nos levam a uma questão que aparece como recorrente em suas falas: a necessidade de pesquisa. Essa referência é muito importante, pois nos mostra que os alunos começam a compreender o ensino como uma prática constante de investigação. "Agora já sei como posso pesquisarpara ensinar. Assim como foi essa dança que fizemos hoje a ciranda de Paraty, tudo que a gente aprende aqui é ótimo para a gente passar pro aluno depois vai ser uma troca de informaçóes tudo que eu aprendi aqui e eu sei que também vou aprender com ele".

A dança passa a ser compreendida como produto de um contexto e de um processo social, histórico e todas as suas complexas relaçóes com o meio e com os elementos inseridos neste. Desta forma, o aluno-mestre passa a perceber que por intermédio desta prática encontra o espaço para o desenvolvimento de um trabalho com inúmeras possibilidades de aprendizado tanto para si como para seus alunos. "Além de tentar apresentar para o aluno e introduzir este conbecimento, a gente também vai aprender. Por exemplo, o Jongo eu não sabia o que era Jongo, isso nunca foi me passado. Agora já sei como posso pesquisar para ensinar".

Durante as respostas da questão anterior surgiram algumas relacionadas ao preconceito. "A PPI trouxe muitos conhecimentos, mas esbarrei em alguns limites, o Jongo, por exemplo, eu disse: - nada a ver, isso é macumba brother. E foi diferente do que eu pensava, agregou muito conhecimento, eu pensei, que é isso!!! E foi completamente diferente [...]".

Foi perguntado aos alunos se pessoalmente identificaram algum tipo de preconceito ao lidar com o conteúdo. As questóes religiosas e as de gênero foram as que mais apareceram. No decorrer da disciplina, os alunos foram provocados em diversos momentos a participarem de discussóes e reflexóes a respeito de como as questões religiosas precisam ser incluídas no contexto escolar como forma de promover debates sobre a diversidade. Com o tema da pluralidade cultural colocou-se em evidência as referências relativas às diferentes composições étnicas responsáveis pela composição de nossa sociedade. Contudo, mesmo avançando neste processo, pudemos ver que a transformação e a reprodução podem coexistir mesmo dentro de uma única fala. "A questão do preconceito aconteceu comigo. Um colega viu o meu post do facebook e falou: - você virou macumbeira? (risos) Eu fiquei revoltada!!! Pô, a gente estuda tanto [...]".

Durante o processo ficou bastante claro que ocorreu uma ressignificação do conteúdo nesta esfera dentro do grupo. $\mathrm{O}$ relato feito por um dos alunos durante a discussão a respeito da reação das pessoas que passavam pelo grupo de alunos durante a oficina de contação de história realizada na estação ferroviária reforça essa afirmação. Os alunos afirmaram que na percepção deles as pessoas que passavam olhavam com estranhamento e receio imaginando que ali estaria acontecendo algum tipo de ritual religioso. "[...] com o Jongo o preconceito rolou tanto com as pessoas que estavam praticando, quanto com as de fora".

Podemos levantar aqui uma questão acerca desta afirmativa: será que realmente esse entendimento a respeito das pessoas que passavam pela apresentação era esse? Ou os alunos projetaram nestas essas pessoas suas próprias questões pessoais? Devemos relembrar alguns problemas ocorridos durante a montagem e a apresentação da oficina. Alguns alunos demonstraram resistência quando souberam que iriam se caracterizar para participar e dançar o Jongo, mas após as inúmeras discussões, reflexões a respeito do tema e a adesão à participação da maioria dos alunos, a situação foi se modificando. Mesmo assim alguns poucos alunos se negaram a participar.

As questóes religiosas estiveram presentes em todo o processo de construção da oficina, porém nos relatos do grupo focal elas já se apresentaram mais elaboradas por alguns membros do grupo. Os alunos-mestres puderam identificar a oportunidade que vivências como as que tiveram podem proporcionar um espaço para mudanças de conceitos anteriormente estabelecidos, da mesma forma que ocorreu com eles, como afirmou 
um deles. A experiência real da dimensão das transformações que podem ocorrer nos processos educativos abre para esses alunos novas perspectivas. "[...] Ai é que entra a desconstrução. Qualquer um de vocês não imaginaria a mesma coisa se não soubesse o contexto da situação".

Ainda em relação ao preconceito, as relações de gênero e de orientação sexual apareceram em vários momentos durante a entrevista do grupo focal. Um dos relatos destaca como os significados se transformaram a partir da vivência de uma oficina de balé, vivenciada na disciplina dança, no período anterior. "Quando eu soube que iria fazer balé clássico imaginei todo mundo pulando, saltitando de sainha mais acabou que não foi... Experimentamos a técnica do balé, o alongamento e alguns passos [...]".

A relação do homem com a dança dentro do curso ainda é cercada por tabus e desentendimentos, o que reforça é o fato de a sociedade em seu ainda associar dança a balé e bailarino aos estereótipos de gênero culturalmente construídos. Mesmo percebendo o esforço dos alunos em estabelecerem relações mais abertas e esclarecidas a respeito do tema, as próprias falas 'contra' o preconceito mostram uma contradição: “ $O$ preconceito rolou mais com o Jongo. Talvez as pessoas parassem para ver se estivesse lá um monte de homem de tutu e vestido de bailarino [neste momento outro aluno fala:- um monte de gay!]... O que eu estou querendo dizer é que a questão de gênero pesou menos do que a da religião. Se fosse um monte de menino vestido com roupinha de bailarina de tutu ninguém iria ligar".

Outra fala reforça a mesma ideia: "Não preconceito, mas um pouco de vergonha... Quando soube que eu ia ter aula de balé clássico me imaginei de tutu (risos) [...]”.

Essa realidade, que está presente ainda hoje em nosso campo de atuação, representa um obstáculo permanente no percurso da dança na educação física, que, no entanto, pode ser amenizado no desenvolvimento do trabalho. Um elemento de grande importância nesse processo são as experiências de caráter estético, que auxiliam no processo de ressignificação do conteúdo. Assim, para além do processo cognitivo, os alunos relatam como a fruição da dança e a emoção de se apresentar influenciaram em seu processo de formação. "[...] um frio na barriga de tentar apresentar o melhor trabalho... Se a gente voltasse um pouco atrás, na mesma semana quando apresentamos o trabalho em Campo Grande, ninguém esperava que o trabalho que apresentamos na quadra iria ser daquele jeito. Foi excelente! E quem fez essa diferença foi o comprometimento por parte dos alunos [...]. Sinceramente eu sou um pouco timido pra essas coisas e estava muito sem graça, mas pensei eu quero apresentar, mostrar equebrar esse paradigma. Foi bom pra gente e foi bom pra todo mundo que passou. Eo arrepio que eu falei pra senhora que eu senti foi quando eu pensei: caramba, deu certo!!!".

Os relatos reforçam a importância da fruição estética neste processo. Um importante ponto a ser levantado é o fato deste objetivo não ser tão enfatizado na educação física. Isto se constata na análise dos PCN-EF que abordam a questão da apreciação estética, porém, de forma muito rasa, limitando-se à proposta de "[...] adotar atitudes de valorização e apreciação dessas manifestações expressivas”. (Brasil, 1997, p. 39).

A fala do grupo nos mostra que tanto as questões de caráter estético como também o resultado de um trabalho construído coletivamente geram um sentimento grande motivação e pertencimento dos alunos. "Quando a senhora falou a primeira vez o que a nossa turma iria fazer, o Jongo, a nossa turma náo levou muito a sério... Depois que as pessoas viram acontecer foi outra história... Em Bonsucesso (se referindo à apresentação na estação de trem), foi como se a gente estivesse em outro mundo, entendeu? Foi surpreendente pra todo mundo. Ai as pessoas caíram na real e pensaram:- Pôxa, é isso mesmo tá dando certo o que a professora falou, não é brincadeira. Então todo mundo começou a levar mais a sério... Depois da primeira apresentação o pessoal já mudou o pensamento. Quando está na teoria só na sua imaginação as pessoas não levam a sério, muita gente falou que não ia na sexta-feira para a outra unidade da faculdade, e praticamente estava todo mundo lá, as pessoas ficaram com vontade de ir [...]".

Considerando os temas que despontaram no grupo focal, evidenciam-se alguns pontos como marcas mais relevantes deste processo de intervenção pedagógica. Confirma-se que a expectativa inicial dos alunos era a de que a disciplina apresentasse um repertório pronto ou técnicas de trabalho que pudessem ser codificadas e repetidas como método de ensino para serem reproduzidos. Pode-se relacionar essa questão apontada pelos 
alunos ao conceito de texto de Marques, que faz uma crítica à dança que se vê nas escolas, em geral uma sequência de passos marcados produzidos como uma manifestação linguística da ideia do professor-criador, "o que coloquialmente tem sido chamado de coreografia". (Marques, 2010, p.149).

A pesquisa realizada mostra que um dos pontos mais complexos neste processo de construção pedagógica é a transformação deste entendimento a respeito do 'texto pronto'. Como se produzir um texto coreográfico a partir das vivências pedagógicas realizadas, utilizando os elementos produzidos pelos alunos da escola? Nas atividades, quando os alunos foram levados a refletir sobre a importância do processo de construção em detrimento da cópia de movimentos, apareceram alguns questionamentos. Se não se deve ensinar coreografia, como vou ensinar as movimentações do Jongo para meus alunos? Neste caso, percebemos que os alunos, ao longo do curso, foram compreendendo possibilidades de se ensinar/aprender movimentos específicos de dança ou signos já criados, porém não restringir o processo a somente isso.

No discurso construído pelo grupo focal e nas práticas apresentadas pelos alunos ao longo da disciplina, nota-se uma crescente compreensão do grupo acerca da importância de que os repertórios tradicionais (textos relativamente prontos) não são roteiros a serem 'dominados' por um professor transmissor e sim fragmentos textuais a serem pesquisados e explorados pelos alunos da escola, mediante a ação de um professorproblematizador. Neste sentido perceberam ser possível identificar de forma consciente e investigativa que fatores de movimento estão envolvidos nos passos tradicionais, além de sua associação ao contexto que produziu este conhecimento.

A partir de suas vivências pessoais, os sujeitos deste grupo lidaram com questões que podem balizar o seu fazer pedagógico em suas futuras experiências profissionais, tais como: por que os movimentos são realizados desta forma? Em que contexto essa dança foi criada? Quem os dançava? Que significado os movimentos traziam dentro do contexto criado? Será que podemos realizá-los de maneiras diferentes? Como é o 'meu' movimento no jongo? Que dificuldades encontro? Como posso realizar os movimentos de forma mais harmônica? Demonstraram assim que compreenderam ser necessário buscar um aprofundamento com relação ao 'o quê' ensinar, 'como' ensinar e 'por que' ensinar. A partir de um processo dialógico com o aluno pode-se apontar objetivos e delinear trajetórias para se chegar aos conhecimentos que emergem como necessários no ambiente educativo.

A maioria dos alunos investigados, como havia sido identificado no questionário inicial da disciplina, dizia não possuir nenhuma vivência anterior em dança. Obviamente, esses alunos já tinham visto dança, conheciam e muitos até diziam gostar de dançar, porém em função de sua experiência limitada, acabavam por serem 'consumidores' das danças tratadas na mídia e ou nas academias. O desafio da disciplina foi suscitar a compreensão de que as práticas corporais constituem-se como produto sociopolítico e cultural, criando uma relação menos ingênua a respeito das práticas corporais e da educação somática, dando condição de se estabelecer novas teias de relações e novos significados para esse conhecimento.

A partir desta reflexão outro ponto abordado pelos alunos nos relatos do grupo focal foi a importância pesquisa. Ao perceber esta necessidade de pesquisar, os alunos-mestres começam a estabelecer a relação entre as práticas corporais, antes entendidas como meros gestos reprodutivos, e uma vasta rede multidisciplinar de conhecimentos, que poderiam ser abordados nas propostas em dança. A possibilidade de vasculhar o contexto a ser trabalhado, despertou a condição de perceber os inúmeros temas vinculados ao universo da dança e auxiliou na reconstrução dos conceitos relacionados. Essa reorganização dos próprios conceitos a partir do contexto encontrado remete à ideia da quadra articuladora proposta por Marques (2010), problematizar, articular, criticar e transformar. Ao serem levados a perceber 'como' se desenvolve o processo de ensino, neste caso, foi essencial para despertar e criar condições para que descobrissem em sua própria vivência a importância do processo investigativo e assim incorporar isso à sua futura prática profissional.

Outro ponto importante levantado pelo grupo focal foi a respeito da necessidade de conhecimento de técnicas específicas para o trabalho da dança na escola. Ao mesmo tempo em que esses alunos apontaram que a disciplina não ofereceu uma grande quantidade de recursos técnicos para sua instrumentalização profissional, 
conseguiram identificar em Laban uma alternativa para o desenvolvimento dos trabalhos. A metodologia de Laban foi relacionada às diferentes atividades criadas por esses alunos, reafirmando a proposta do autor que valoriza as experiências individuais e livres de padrões pré-estabelecidos. Os alunos foram levados a perceber que é necessário explorar o potencial criador, expressivo e espontâneo dos sujeitos dançantes.

A análise dos movimentos, também foi apontada como alternativa a passos de dança já existentes ou sequências coreográficas. Sendo assim, os alunos do grupo tiveram condiçóes de identificar nesta metodologia um instrumento de suporte para elaboração do trabalho em dança. Durante o processo de intervenção pedagógica, os alunos-mestres demonstraram algumas dificuldades nas escolhas do subtexto associados à metodologia de Laban, bem como também buscar novas maneiras de propor atividades alternativas ao texto pronto. À medida que foram realizadas interferências da professora, os alunos identificaram como poderiam enfatizar os fatores de movimento e as harmonias espaciais nas atividades criadas. Desta forma, Laban funcionou como uma referência 'técnica' para a produção dos movimentos propostos nas atividades.

Laban deixa claro 'como' alcançar a exploração e o conhecimento do movimento humano, e com condição de conceituar esses objetivos como 'resultados úteis'. Podemos afirmar que a partir dessas intervenções os alunos começaram a compreender de que forma é possível se buscar alternativas aos movimentos codificados. A reconstrução de suas próprias atividades é a concretização da proposta metodológica, a partir de uma situação real, tornou esta mais facilmente compreendida e reconhecidamente útil para esses alunos como alternativa de trabalho quando estes identificaram dificuldade na busca de estratégias.

Parece que a 'técnica livre de dança' proposta por Laban foi percebida pelos alunos como uma ferramenta a ser utilizada em seu fazer pedagógico. Um aspecto que pode ter facilitado este entendimento pode estar relacionado ao fato de que os conceitos pautados aos fatores espaciais e de movimento, trazidos pelo autor em sua proposta de trabalho, já estarem presentes no universo de conhecimentos tratados pela Educação Física e de suas práticas corporais. Desta forma, a apropriação e o entendimento das harmonias espaciais e dos fatores de movimento podem ser mais facilmente incorporados por esses alunos do que técnicas tradicionais e rígidas de dança. A conduta educativa baseada na experimentação e na liberdade de expressão parece ter facilitado a desconstrução da ideia do texto pronto.

Outra questão que foi marcante na fala dos alunos, diz respeito a uma expectativa de que fossem ser dadas mais aulas práticas durante a disciplina. $\mathrm{O}$ fato de esses alunos se confrontarem com um grande número de aulas teóricas gerou, no grupo, certo estranhamento. Este relato pode estar relacionado ao fato de os alunos do curso de educação física chegarem à universidade com a expectativa de encontrar em sua formação grande número de aulas práticas e não atribuírem à devida importância à fundamentação teórica. Pudemos identificar que esse estranhamento de uma grande ênfase na teoria não está relacionado somente à dança, isso se manifesta também com outros conteúdos presentes em sua formação, nas disciplinas relacionadas ao jogo, ao esporte, à luta e à ginástica. Essa realidade nos mostra que esses alunos a priori reproduzem o conceito dualista estabelecido no senso comum a respeito das práticas corporais, desvinculado-as das atividades intelectuais. À medida que se deparam com uma realidade diferente e que exige uma sistemática necessidade de aprofundamento teórico, percebem que seu percurso profissional deve ser estruturado por trajetórias bem diferentes das imaginadas inicialmente.

Essa reconstrução a respeito da realidade da educação física é crucial para uma boa formação do profissional: modificar sua percepção a respeito das atividades práticas, tão esperadas, e começar a compreender a grande importância da fundamentação teórica vinculadas a elas. Somente dessa forma, essas práticas poderão ser transformadas em instrumento para sua futura ação profissional.

Outro aspecto relevante nas falas do grupo focal diz respeito ao fato de a dança representar para maioria um terreno desconhecido e, portanto, intimidador. De uma forma geral, os alunos do curso de educação física inicialmente mostram-se pouco à vontade para realizar as atividades de dança de forma livre. As aulas iniciais são marcadas por falas e reações que deixam claro o quanto esse conteúdo ainda é incômodo e pouco familiar. Quando são indagados a respeito de suas vivências e conhecimentos sobre o conteúdo por diversas vezes a 
falta de experiência vem justificada pelo relato de considerarem que não têm habilidade para dançar. Parecem não perceber que a falta de experiência é que gera a alegada falta de habilidade, já que aqui desconsideramos qualquer condição inatista para as possibilidades de aprendizagem na dança. Essa situação, de alguma forma descreve um paradoxo entre o cenário encontrado no ensino superior e da escola como um todo: esses alunos são fruto de uma determinada concepção de dança na escola, que agora se apresenta a eles como algo com o que devem lidar (e, preferencialmente, transformar) em sua futura vivência como docente.

As questões relacionadas ao preconceito se apresentaram muito presentes nos relatos do grupo focal reforçando assim as reflexões de Marques (2006) quando toca na questão de gênero. As questões relacionadas ao gênero ainda geram alguns desentendimentos, como percebemos durante a fala dos alunos-mestres. A dança, em muitos momentos do relato do grupo e como já relatado anteriormente, foi relacionada ao balé clássico, que, por sua vez, era relacionado às bailarinas de tutu.

Em outro momento, quando um integrante do grupo relatava a questão do preconceito religioso, identificou-se que as pessoas que passavam na estação no momento da apresentação da oficina de contação de história, pensavam que os alunos estavam fazendo algum tipo de ritual religioso. "É macumba, mas se fosse um monte de bailarino vestidos de tutu..."; neste momento, outro aluno faz uma interferência "um monte de gay... ninguém iria ligar...". É claro que esses alunos identificam como um motivo de estranhamento homens que dançam balé. A identificação da dança com o balé, e o decorrente preconceito homofóbico que daí advém, mostra o quanto estes conceitos estão arraigados. Mesmo esses alunos tendo oportunidade de reconstruir os significados e sentidos da dança, nos discursos esse preconceito ainda aparece tão solidificado, que sua desconstrução se mostra uma tarefa árdua, demandando esforço e amadurecimento. Essa desconstrução também depende de transformações da própria sociedade, por isso seu reflexo nos espaços educacionais deve ser tratado como conteúdo de relevância, de forma que a escola possa dar sua contribuição.

Além da recorrente relação complexa entre dança e gênero, neste estudo se destacou ainda com mais ênfase a questão étnico-racial. Um conteúdo importante integrante da disciplina é o tema transversal pluralidade cultural, que foi incrementado com a proposta de trabalho específica para aquele semestre: o desenvolvimento de um trabalho para o evento BrasileirAfro. Assim, surgiram situações que geraram discussões acerca da influência dos valores religiosos na construção das relações com referências culturais afro-brasileiras. No Brasil, manifestações da cultura das danças afro-brasileiras estão ancoradas em valores ligados, direta ou indiretamente, às religiões trazidas da África no período de escravização. Exemplos de manifestações que estão ao mesmo tempo ligadas ao movimento corporal e à religião podem ser vislumbrados no maculelê, no jongo, na capoeira, no folclore, nas danças com matriz africana. Assim, a associação de danças com matriz africana remete ao preconceito presente na sociedade brasileira em relação aos negros. Em muitos casos, o preconceito está camuflado como uma discriminação ao candomblé, a umbanda, à macumba, ou seja, religiosa. Mas, na verdade, é um preconceito étnico-racial. Conforme Paradiso (2010, p. 1) “o 'culto' aos deuses negros afronta as mentes alienadas que, mesmo 'tolerantes', teimam que Deus e seu culto só podem ser brancos”. Essas discussões deram condições para o grupo refletir de que forma a escola e a educação física podem contribuir para a modificação deste cenário ao tratar dos temas religião e folclore. Essas reflexões corroboram as ideias de Silva e Silva (2009, p. 555) essas podem “[...] abrir novos horizontes e contextos desconhecidos, e incitar ao diálogo e ao respeito à diversidade".

A questão relacionada ao preconceito religioso em alguns momentos foi reproduzida pelo grupo no decorrer do processo de criação do trabalho, como no caso relatado dos alunos evangélicos que revelaram incomodo inicial no desenvolvimento do tema. Ao tratar da cultura afro-brasileira, a associação à religião emerge como questão principal. Silva e Silva (2009) afirmam que o fato de hoje encontrarmos um representativo número de professores e alunos influenciados pelas religiões neopentecostais tem refletido na forma de se tratar alguns temas relativos à cultura popular e ao folclore, principalmente os relacionados à cultura afro-brasileira. É comum, quando se fala das manifestações culturais, que se crie algum nível de tensão que muitas vezes leva os alunos a rejeitá-las, já que se dá “[...] o afastamento e a autoexclusão que 
ocorrem em razão de considerarem essas manifestações folclóricas apologia a crenças diferentes das suas, ou por considerarem-nas manifestações demoníacas”. (Silva; Silva, 2009, p. 560).

Pode-se identificar essa realidade entre alunas que participaram do grupo focal, que nos dias das apresentações se negaram a se caracterizar e a 'entrar' na atividade de forma efetiva, limitando-se às tarefas de produção. Este fenômeno de autoexclusão das aulas em que a matriz africana está presente tem se intensificado no início do século XXI (Santos, 2016). Mesmo assim, o discurso de uma delas, durante a entrevista do grupo focal, foi bastante enfático ao apontar de forma crítica as relações preconceituosas existentes na abordagem desse tema na escola. Percebemos assim que os futuros professores foram incitados a refletir sobre sua importância dentro do processo de resgate da história e da cultura brasileira, ao mesmo tempo em que tiveram que lidar com dogmas colocados por sua formação religiosa.

O tema propôs que os alunos-mestres buscassem ampliar seus conhecimentos a respeito das influências que os diferentes componentes étnicos trouxeram como contribuições para o acervo cultural brasileiro. Também puderam perceber como os reflexos destas na construção étnica das relações sócio-culturais e econômicas são reproduzidos hoje em nosso contexto social nas relações discriminatórias que provocam a exclusões sociais sistemáticas. O processo de construção da oficina de contação de histórias em muito contribuiu para a ressignificação deste tema e trouxe para uma grande parte do grupo a superação ou pelo menos abriu espaço para essa superação, colocando-os diante de um incômodo que os fez refletir sobre as relações entre seu papel profissional e suas crenças.

A proposta de contextualização, trazida por Marques (1999), ajudou os futuros professores a investigarem e refletirem a respeito da relação dos desentendimentos existentes na relação entre religião e cultura. A idéia de escola laica e o respeito à diversidade funcionou como ponto de equilíbrio para os debates que trouxeram diferentes pontos de vista, entendendo a escola como um espaço para o acolhimento e reflexão das diferenças. A diversidade de opiniões e reflexões enriqueceu a dinâmica e abriu espaço para pesquisa e experiência corporal da dança. Neste caso, o Jongo marcou o início do processo de construção que culminou na oficina de contação de história.

Outro ponto destacado pelo grupo foi a valorização que atribuíram à fruição estética. A experiência, em particular a vivência da apresentação de um trabalho criado e interpretado por todo o grupo, vinculada ao conhecimento teórico tornou possível criar sentidos e ressignificar esse conteúdo como algo que valha a pena de ser vivido e, portanto, oportunizado aos futuros alunos. Durante a preparação da oficina, foram ocorrendo transformações no envolvimento destes alunos com a disciplina, que culminou com dia da apresentação da oficina. Esta adesão emocional poderia estar presente em qualquer grupo que se envolve com a preparação de uma obra artística e depois tem o prazer de vê-la concluída. Contudo, este processo foi mediado pelo comprometimento consciente com uma determinada visão de educação e de sociedade.

Pode-se dizer que, como afirma Marques (2010), durante a realização do evento esses alunos estavam "pronunciando" o mundo e engajados em construir novos sentidos relacionados às questões envolvidas no tema tratado. O caso do aluno que toma posse do microfone e relata que, mesmo sendo evangélico, se sente íntegro ao afirmar que valorizar a cultura afro-brasileira não interfere em sua crença religiosa, é exemplar. É de extrema importância que se promovam discussões acerca do tema dança e religião, para que se desfaçam as relações fantasiosas e excludentes, que corroboram o enfraquecimento da cultura popular em nosso contexto escolar e na sociedade.

\section{CONCLUSÕES}

O objetivo deste estudo foi analisar o processo de apropriação dos conhecimentos relativos à dança, ao longo da vivência dos alunos em uma disciplina intitulada prática pedagógica da dança, que faz parte de um curso de licenciatura em educação física, na cidade do Rio de Janeiro. 
As evidências captadas nos relatos apontam quatro principais apropriações: 1) a modificação de percepção a respeito das atividades práticas e compreensão da importância da fundamentação teórica vinculadas a elas; 2) o fato de a dança representar para maioria um terreno desconhecido e, portanto, intimidador gerando insegurança, medo de exposição e resistência à participação nas atividades; 3) o preconceito que se apresenta relacionado às questões étnico-raciais, de gênero e religiosas; 4) a valorização à fruição estética.

Modificar a percepção a respeito das atividades práticas, tão esperadas, e começar a compreender a importância da fundamentação teórica vinculadas a elas foram duas das características mais importantes dos relatos surgidos nesta investigação.

Outro aspecto relevante diz respeito ao fato de a dança representar para maioria um terreno desconhecido e, portanto, intimidador. O relato dos alunos reforça que até mesmo as modalidades de dança esperadas na disciplina eram completamente desconhecidas. Como apontam as pesquisas citadas anteriormente, a primeira associação feita pelos alunos quando sabem da existência da disciplina dança é pensar em balé clássico. Isto gera insegurança, medo de exposição e acaba criando certa resistência dos alunos na participação das atividades. Somente as reflexões, o conhecimento, a experiência foram criando um espaço mais confortável para romper com os conceitos pré-estabelecidos e ajudaram a criar o envolvimento necessário que tornou possível a superação das dificuldades.

As questóes relacionadas ao preconceito se apresentaram muito presentes nos relatos do grupo focal reforçando que as questóes étnico-raciais, de gênero e religiosas estão presentes com grande visibilidade quando se desenvolve conteúdos relacionados à dança.

A questão relacionada ao preconceito religioso em alguns momentos foi reproduzida pelo grupo no decorrer do processo de criação do trabalho, como no caso relatado pelos alunos evangélicos que revelaram incomodo inicial no desenvolvimento do tema. Ao tratar da cultura afro-brasileira, a associação à religião emerge como questão principal.

Outro ponto destacado pelo grupo foi a valorização que atribuíram à fruição estética. A experiência, em particular a vivência da apresentação de um trabalho criado e interpretado por todo o grupo, vinculada ao conhecimento teórico tornou possível criar sentidos e ressignificar esse conteúdo como algo que valha a pena ser vivido.

O grupo focal nos deu subsídios para afirmar que a disciplina pode ter oferecido aos alunos ferramentas importantes para pensar sua futura prática profissional no que diz respeito ao ensino da dança. Porém tão importante quanto isso é perceber que estes alunos não criaram uma expectativa ingênua a respeito da realidade que encontrarão. A partir das trocas e reflexões a respeito dos temas tocados e tratados na disciplina, conseguiram estabelecer uma leitura crítica e consciente do cenário escolar. Isso ficou bastante nítido quando uma aluna afirma que, com base nos conteúdos aprendidos, percebe a condição de realizar um trabalho que a permita ir além das propostas tradicionais da escola, mas tem ciência de que irá se deparar muitas vezes com um sistema escolar que não valoriza e restringe essas ações.

Contudo podemos afirmar que novas perspectivas foram abertas para esses profissionais em formação. Resta-nos indagar se realmente sua formação contribuirá para que de fato realizem as mudanças necessárias que tanto podem colaborar para a reconstrução de conceitos e a valorização profissional.

Conflito de interesse: Os autores declaram não existir conflito de interesse.

\section{REFERÊNCIAS}

Alves-Mazzotti, A. J. \& Gewandsznajder, F. (2000). O método nas ciências naturais e sociais: pesquisa quantitativa e qualitativa. São Paulo: Pioneira.

Brasil (1997). Secretaria de Educação Fundamental. Parâmetros curriculares nacionais: Educação Física. Ministério da Educação e Cultura. Brasília: MEC/SEF. 
Campos, M. A. A. (2009). Histórias das práticas de dança na escola de Educação Física da UFMG. Revista Brasileira de Ciências do Esporte, 31(1), 193-208. Disponível em http://revista.cbce.org.br/index.php/RBCE/article/ view/643. Acesso em: 20 abr. 2018.

Coletivo de Autores. (1992). Metodologia do ensino de Educação Física. Cortez Editora.

Correia, A. M., Votre, S. J. \& Oliveira, A. B. C. (1998). Dança e Educação Física: uma abordagem histórica da disciplina Dança na Escola Nacional de Educação Física e Desportos. In: Anais do VI Congresso Brasileiro de História do Esporte, Lazer e Educação Física, 1, 168.

Daolio, J. (1997). Educação Física brasileira: autores e atores da década de 80. (Tese de Doutorado). Faculdade de Educação Física da Universidade Estadual de Campinas.

Gaskell, G. \& Bauer, M. W. (2002). Pesquisa qualitativa com texto, imagem e som. Petrópolis: Vozes.

Gil, A. C. (2004). Como elaborar projetos de pesquisa. São Paulo: Atlas.

Gomes, A. S. M. (2007). Uma análise fenomenológica do dançar nos discursos dos formandos em Educação Física. (Dissertação de mestrado). São Paulo (SP): Universidade São Judas Tadeu.

Laban, R. (1978). O dominio do movimento. São Paulo: Summus.

Marques, I. A. (1999). Dança e educação. Revista da Faculdade de Educação, 16 (1-2), 05-22.

Marques, I. A. (2001). Ensino de dança hoje: textos e contextos. São Paulo: Cortez.

Marques, I. A. (2006). Dançando na escola. São Paulo: Cortez.

Marques, I. A. (2002). Revisitando a dança educativa moderna de Rudolf Laban. Sala Preta, 2, 276-281. Disponível em: http://www.revistas.usp.br/salapreta/article/view/57104. Acesso em: 20 abr. 2018.

Marques, I. A. (2010). Linguagens da dança: arte e ensino. São Paulo: Digitextos.

Pacheco, A. J. P. (2008). Educação Física feminina: uma abordagem de gênero sobre as décadas de 1930 e 1940 . Revista da Educação Física/UEM, 9(1), 45-52.

Paradiso, S. R. (2010). Educação, literatura, diversidade étnico-cultural religiões afrobrasileiras: o diálogo possível. Revista Interletras, 2(13), 1-16. Disponível em: https://s3.amazonaws.com/academia.edu.documents/33844116/CANDOMBLE_EDUCACAO.pdf?A WSAccessKeyId=AKIAIWOWYYGZ2Y53UL3A\&Expires=1556295767\&Signature $=$ Hln0P4FUTPhaYp LIZ0F07s1 mdUI\%3D\&response-content-disposition=inline\%3B\%20filename\%3DEDUCACAO_LITERA TURA_DIVERSIDADE_ETNICO-C.pdf. Acesso em: 26 abr. 2019.

Sandin Esteban, M. P. (2010). Pesquisa qualitativa em educação: fundamentos e tradições. Porto Alegre: AMGH.

Santos, R. B. (2016). "Da igreja": uma análise da metáfora religiosa nas aulas de educação física escolar. (Dissertação de Mestrado). Programa de Pós-graduação em Ciências da Atividade Física da Universidade Salgado de Oliveira.

Silva, J. E \& Silva, C. A. F. (2009). Educação física, folclore e religião: relações e interferências. Revista da Educação Fisica/UEM, 20(4), 555-567. DOI: 10.4025/reveducfis. v20i4. 6323. 